\title{
Which difficulties and resources do vocational teachers perceive? An exploratory study setting the stage for investigating teachers' resilience in Switzerland
}

\author{
Elena Boldrini ${ }^{\mathrm{a}}$, Viviana Sappa ${ }^{\mathrm{a}}$ and Carmela Aprea $^{\mathrm{b}}$ \\ aSwiss Federal Institute for Vocational Education and Training, Lugano, Switzerland; 'business School, \\ University of Mannheim, Germany
}

\begin{abstract}
Based on an ecological view of teacher resilience, the paper investigates perceived difficulties and resources among vocational education and training (VET) teachers as a first step for investigating teachers' resilience. Given the substantial shortage of theoretical and empirical studies on this population, more research on resilience among VET teachers is necessary and relevant. In this exploratory qualitative study, interviews with VET teachers in Switzerland ( $n=37$ ) sought to identify the specific challenges faced by teachers, the resources to be addressed. As well as confirming the different critical challenges and protective factors emerging from the literature review, the results identify difficulties and resources specific to VET teachers in Switzerland. In terms of critical challenges at a macro-contextual level, teachers' low social recognition is emphasised. Moreover, exposure to curricular reforms generates stress and pressure related to the required standardisation of content and subject changes. At a micro-system level, we detected teachers' frustration in relation to students' low vocational motivation and maturity and specific emerging instructional challenges in vocational subject teaching. In terms of resources, teachers perceived the possibility of diversifying their professional role by alternating school and extracurricular activities as a supportive factor. The results provide a basis for more extensive quantitative study investigating relationship among adversities and resources and resilient strategies.
\end{abstract}

\section{ARTICLE HISTORY}

Received 12 July 2017

Accepted 31 August 2018

\section{KEYWORDS}

Teachers' resilience; vocational education and training; difficulties; resources

\section{Introduction}

Extensive research confirms the threatening nature of the teaching profession as a highly demanding job, intellectually, emotionally and relationally (Day \& Gu, 2009; Gu, 2014; Mansfield, Beltman, \& Price, 2014; Richardson, Watt, \& Devos, 2013; Schelvis, Zwetsloot, Bos, \& Wiezer, 2014). However, some teachers seem able to cope successfully with these professional challenges, maintaining a positive outlook despite all the adversities they naturally encounter. The increasing research interest in this

CONTACT Elena Boldrini elena.boldrini@sfivet.swiss E Swiss Federal Institute for Vocational Education and Training SFIVET, Via Besso 84, Lugano-Massagno CH-6900, Switzerland

4 Supplementary data can be accessed here. 
population has been principally concerned to identify the resources and strategies that most support teachers' resilience - that is, their capacity 'to maintain [...] commitment to teaching despite challenging conditions and recurring setbacks' (Brunetti, 2006, p. 813).

Studies of teacher resilience have looked at teachers in different categories, including primary school, secondary school and special education. In addition, teacher resilience has been investigated in at-risk settings such as inner city schools, schools attended by students from poor families or in resource-constrained societies (see e.g. Ebersöhn, 2014). However, there is little research in this regard on vocational teachers and schools.

The present study forms part of a large quali-quantitative research project that aims to bridge this gap by investigating teacher resilience in vocational education and training (VET). Specifically, as the first stage of the project, this study investigates difficulties encountered by vocational school teachers in their professional life and the supporting resources that keep them satisfied and engaged despite those adversities. In this perspective, the present paper represents a necessary empirical basis in order to explore the nature of difficulties and resources that characterise VET teachers' profession on which to build a quantitative research on the resilient strategies in combing challenges and resources.

To that end, we begin by elaborating a theoretical framework for the study based on a socio-ecological conception of teachers' resilience. Second, we argue for the importance of exploring resilience among vocational school teachers. Third, we detail the research questions and methodology applied here. Finally, after presenting and discussing our findings, we outline some implications for teacher training.

\section{A socio-ecological view of teacher resilience}

Adopting a socio-ecological perspective (Day, 2014; Mansfield et al., 2014; Rutter, 2006; Ungar, 2012) as the principal theoretical background, we conceptualised teachers' resilience as successful, functional and positive adaptation (Masten, Best, \& Garmezy, 1990) resulting from the dynamic (Luthar, Cicchetti, \& Becker, 2000) and continuous interplay among (1) perceived threatening stressors and difficulties, including individual contextual conditions and events, and (2) perceived protective resources, including individual attitudes and abilities and contextual resources.

Perceived difficulties are understood as stressors to which teachers are exposed during their professional practice. It must be emphasised here that the perceived nature and intensity of these events as threatening and challenging depends on the personal interpretation of the individual, based on their values, beliefs, biography, knowledge and so on (e.g. Gibbs \& Miller, 2014). The critical challenges most frequently reported in the literature include both contextual conditions (e.g. school, society) and individual difficulties (e.g. immediate classroom management), especially in combination with disruptive students' behaviour, unsupportive school leadership, conflicts with colleagues, conflicts between values and actual practices and heavy workload (Beltman, Mansfield, \& Price, 2011; Mansfield et al., 2014).

Perceived resources refer here to factors that enable teachers to maintain a positive profession. Again, it is important to stress the subjective nature of this element, as its 
protective function depends on personal interpretation. Resources may relate to personal or contextual elements, including personal attributes such as sense of motivation, intrinsic motivation and passion for the job and self-efficacy and contextual elements like a supportive school culture, collegiality among colleagues and collaborative school leadership (Mansfield, Beltman, Weatherby-Fell, \& Broadley, 2016). There is evidence that these individual, contextual and organisational factors can combine to support adaptation and a positive response to challenge or adversity (Griffiths, 2014).

Finally, dynamic and reciprocal tensions among the above factors generate differential states and outcomes in terms of professional well-being and positive, negative or dysfunctional adaptation, where resilience refers to positive and functional adaptation. Resilient teachers are often described as those who feel satisfied, engaged and selfcompetent despite professional challenges (Brunetti, 2006; Gu, 2014; Gu \& Day, 2007). For present purposes, we opted to consider job satisfaction, sense of positive engagement with the profession and sense of perceived effectiveness as the main indicators of positive professional adaptation.

On that basis, the larger study was designed to investigate those three main components and their reciprocal relationships. However, while it is plausible to consider the sense of job satisfaction, work engagement and perceived effectiveness as valid and universal for all categories of teachers, we assumed that some perceived adversities and resources would be particular to VET teachers. The next section illustrates and discusses some particularities of the VET context that ground our hypothesis.

\section{Challenges and resources for teachers' resilience: possible peculiarities of VET teachers}

Vocational school teachers have rarely been included in studies of teachers' resilience or, more generally, of teachers' well-being. Other studies investigating VET teachers have tended to focus on one specific challenge, with no overview of those critical events or situations encountered by that population, or of supporting resources that enable them to successfully face those adversities (e.g. Vähäsantanen \& Eteläpelto, 2009). We believe it is worthwhile to investigate the critical challenges and resources particular to VET teachers for at least three reasons.

First, as shown by studies in several countries, VET students are more challenging in terms of both motivation and achievement (Bonica \& Sappa, 2010). In particular, teachers' difficulties may derive from vocational students' perception of VET pathways as a 'second choice' - that is, less gratifying and promising than the more selective school pathways. This seems to emerge in particular in the Italian-speaking part of Switzerland, where the present study is located (Boldrini \& Bausch, 2009). Based on those considerations, we expected that peculiar challenges and resources can be identified related to classroom and teaching management in VET.

Second, at the macro-system level, VET is exposed to specific pressures and demands from both the education system and the labour market, requiring teachers to negotiate these sometimes conflicting requirements. They are also pressed to combine pedagogical skills with competences in the specific professional domain and to keep up to date with professional changes. This pressure is experienced in particular by teachers working in countries with an apprenticeship tradition founded on a 'dual' structure that 
combines theoretical classes at school with practical experience at the workplace, as is the case in Switzerland (Gonon, 2011). In this regard, several countries have promoted curricular reforms to renovate training content and strategies to address new labour market needs. In Switzerland, the 2002 Law on Vocational Education and Training launched wide-scale curricular reform (Swiss Confederation, 2002). As shown by previous research, intensive and additional effort is required to encourage teachers to change their approach to teaching (Dworkin, 2009; Vähäsantanen \& Eteläpelto, 2009). We expected that pressures from both educational and workplace settings have an impact on perceived challenges for VET teachers. Also, peculiar resources could be needed for VET teachers to face with such a pressure.

Finally, vocational teachers frequently combine teaching with other professions that may or may not relate to the subject they teach at school; this is particularly the case in dual VET systems and is especially favoured by Swiss VET teachers, who are required to have relevant prior career experience in their teaching field. Although evidence remains inconsistent in relation to risks or protective effects among teachers holding multiple jobs, there is a strong consensus that this is a crucial factor when investigating teachers' well-being (Guest, Oakley, Clinton, \& Budjanovcanin, 2006). Thus, opportunity to be involved in multiple jobs could play a particular role for VET teachers' well-being.

The three characteristics described above suggest the need for a deeper understanding of peculiar challenges and resources impacting on VET teachers' resilience.

\section{Aim of the study and research questions}

The main goal of the study was to identify the difficulties and resources that vocational school teachers perceive to have the greatest impact on their capacity to adapt positively to the profession. The research questions can be summarised as follows.

(1) Which conditions and situations do VET teachers perceive as particularly adverse for their profession?

(2) Which resources and protective factors do VET teachers perceive as needed in order to cope effectively with those difficulties?

\section{Sample, data collection and analysis}

\section{Sampling}

A total of 37 VET teachers (22 women and 15 men) from the Italian-speaking part of Switzerland participated voluntarily in the study. General characteristics of the participants are summarised in Table 1. The sampling procedure aimed at covering the high variety of profiles in the VET teaching sector. Of these 37 teachers, 8 worked in the commercial training sector, 11 in the healthcare training sector and 18 in the industrial and handcraft sector. Their average age was 50.4 years (SD 9.2). The sample was heterogeneous in terms of both individual variables (e.g. gender, years of teaching experience, cultural vs. professional subjects, functions assumed in school) and contextual variables (e.g. professional sector, kind of training). 
Table 1. Sample: individual and contextual characteristics.

\begin{tabular}{llcc}
\hline & Individual variables & $N$ & $\%$ \\
\hline 1. Gender & Female & 15 & 40.5 \\
& Male & 22 & 59.5 \\
2. Age & Total & 37 & 100 \\
& $25-35$ & 3 & 8.1 \\
& $35-45$ & 9 & 24.3 \\
& $45-55$ & 12 & 32.4 \\
& $55-65$ & 13 & 35.2 \\
3. Teaching experience (years) & Total & 37 & 100 \\
& $<11$ years & 8 & 21.7 \\
& Between 11 and 20 years & 37.8 \\
& $>20$ years & 14 & 40.5 \\
4. Professional roles & Total & 15 & 100 \\
& Exclusively teacher & 37 & 54.1 \\
& Multiple professional roles & 20 & 45.9 \\
5. Subjects taught & Total & 17 & 100 \\
& Professional-related subjects & 37 & 67.6 \\
& Cultural subjects & 25 & 32.4 \\
Contextual variables & Total & 12 & 100 \\
6. Professional sector & & 37 & $\%$ \\
& Industrial and hand-crafted & $N$ & 48.7 \\
& Commercial & 18 & 21.6 \\
& Healthcare & 11 & 29.7 \\
& Total & 37 & 100 \\
\hline
\end{tabular}

Founded on theoretical rather than statistical assumptions, sampling followed the principle of maximum variation as part of judgement sampling procedures (Marshall, 1996).

\section{Data collection}

In semi-structured face-to-face individual interviews, teachers were invited in the beginning to recall critical and experienced professional events in terms of loss of satisfaction, work engagement and sense of competence. Interviewees were asked to detail the concrete challenges identifiable in those situations and, in a second moment, the resources they accessed to face them effectively or not. The third part of the interview was devoted to a general assessment of the perception of challenges and resources impacting on teachers professional well-being (i.e. job satisfaction, work engagement and sense of competence), particularly in the field of vocational training. In Annexe 1, we report the general structure of the interview. All interviews were audiorecorded and transcribed for the purposes of content analysis.

\section{Procedure of analysis}

Interviews were analysed using an inductive categorical content analysis (Krippendorff, 2013), supported by NVivo software, so let emerge content categories from the interviews. As represented in Annexe 2, the procedure implied several phases and it involved three independent researchers.

First, all transcribed interviews were uploaded into NVivo software. The whole text was composed by 37 interviews and a total of 427,383 words.

Second, an inductive categorical analysis was run by 2 independent researchers (researcher 1 and 2) on 10 selected interviews being part of the whole corpus. More specifically, the following steps were followed: 
- The selected corpus was first coded by identifying those portions of text related to difficulties or resources described by interviewees as having significantly impacted on their job satisfaction, engagement and sense of competence. Each selected portion referred to the minimum meaningful unit of text data associated with a single content in terms of perceived difficulties or resources. Such a unit could consist of few words or a sentence or a paragraph depending on the interviewee's way to articulate his/her discourse. Each text portion was considered as a 'reference' by NVivo software.

- A code was attributed to each reference in order to describe the perceived difficulty or resource reported in that reference. Each code was attributed based on the general meaning emerging from the related reference.

- Codes were listed and described by distinguishing those referring to perceived difficulties and those dealing with resources.

- Each code was transformed in a category related to perceived difficulties or resources by providing a name and a brief description (e.g. low social recognition: any references to a perceived low social status of education, school, teachers or VET as a stressful factor).

As a result, we obtained two independent lists of categories related to perceived difficulties and perceived resources.

In the next phase, the two independent lists of categories were dialogically compared and discussed by the two researchers and a preliminary shared coding scheme was defined.

Then, researcher 1 applied the preliminary coding scheme to analyse the whole corpus of interviews. For each code, portions of text (references) were isolated and codified. Consistently with the previous phase of analysis, each reference consisted of the minimum meaningful unit of text data related to a single content in terms of perceived difficulties or resources. An additional code named 'other' was included into the scheme in order to capture any possible difficulty or resource excluded from the preliminary coding scheme.

Furthermore, references clustered in the category 'other' were discussed between researchers 1 and 2. As a result, new content categories were included into the coding scheme and previous categories were revised when needed. The outcome of this phase consisted of the final coding scheme.

Subsequently, the final coding scheme oriented researcher 1 to reanalyse the whole corpus of interviews, while a third independent researcher was asked to code $10 \%$ of the total corpus by using the same final scheme.

The inter-rater agreement was then calculated with respect to the common portion of text coded. Cohen's Kappa values ranged from 0.807 to 1 for the different categories.

Moreover, a total of 1086 references (including 194,321 words, 45\% of the whole corpus) were identified subdivided in 604 about challenges and into 482 about resources.

Finally, categories were clustered into context-related and individual factors. An additional group was created to indicate challenges arising from the nature of the teaching profession, as these were considered neither contextual nor individual. 


\section{Results}

\section{Perceived difficulties}

As reported in Table 2, a total of 24 categories of perceived challenges were identified and clustered into 3 different groups: (a) context-related challenges, (b) individual challenges and (c) teaching-related challenges.

\section{Context-related challenges}

A high proportion of the reported challenges related to life and work context. Based on the ecological approach of Bronfenbrenner (see Bronfenbrenner, 1979), we can allocate those challenges to different levels of the system as follows: (a) macro-system level (referring to the social and policy framework conditions under which teachers work), (b) eso-system level (referring to relationship with other contexts or persons of significance for students), (c) meso-system level (referring to the multiple contexts in which teachers are involved) and (d) micro-system level (referring to contexts where teachers are directly involved).

At the macro-social level, teachers' perceived themselves as workers with poor social recognition. More specifically, the interviewees noted that the complexity of VET teaching is usually underestimated by those who perceive teaching as a simple job [1]. Additionally, people do not realise how much 'energy' is needed in working with

Table 2. Perceived difficulties.

\begin{tabular}{|c|c|c|}
\hline Perceived difficulties & $N$ individuals & $N$ references \\
\hline \multicolumn{3}{|l|}{ Context-related factors } \\
\hline \multicolumn{3}{|l|}{ Macro system level adversities } \\
\hline - Low social recognition & 14 & 25 \\
\hline - Challenging macro-social conditions & 14 & 21 \\
\hline - Educational and work policies & 16 & 41 \\
\hline - Exposure to change (reforms) & 7 & 12 \\
\hline \multicolumn{3}{|l|}{ Eso-system level } \\
\hline - Difficult alliance with students' parents & 5 & 7 \\
\hline - Difficult alliance with students' company trainers & 5 & 5 \\
\hline \multicolumn{3}{|l|}{ Meso-system level } \\
\hline - Difficult work - teacher training balance & 8 & 11 \\
\hline - Difficult work - life balance & 8 & 14 \\
\hline - Pressure from the world of work & 1 & 1 \\
\hline - Difficult collaboration with extra-school services & 4 & 5 \\
\hline \multicolumn{3}{|l|}{ Micro system level } \\
\hline - Lack of a shared culture in school & 17 & 52 \\
\hline - Conflicts with colleagues & 11 & 17 \\
\hline - Lack of collaboration & 16 & 32 \\
\hline - Negative leadership & 17 & 52 \\
\hline - Challenging students & 34 & 117 \\
\hline - Disruptive events & 6 & 8 \\
\hline \multicolumn{3}{|l|}{ Individual challenges } \\
\hline - Excessively permissive or authoritarian approach & 9 & 13 \\
\hline - Excessive emotional involvement & 3 & 3 \\
\hline - Fear of being judged incompetent & 4 & 4 \\
\hline - Perfectionism, sense of duty & 4 & 4 \\
\hline - Lack of openness to change & 5 & 9 \\
\hline \multicolumn{3}{|l|}{ Teaching professional challenges } \\
\hline - Emotional relational labour & 23 & 44 \\
\hline - Instructional challenges & 26 & 73 \\
\hline - Teaching role challenges & 17 & 34 \\
\hline
\end{tabular}


VET students. Moreover, because of the low social status of VET paths, VET schools are often attended by the most challenging and weakest students. This low social recognition may decrease motivation and professional engagement, as the teachers felt that there was a lack of social support for this difficult job.

People think I do nothing the whole day; this is what people think. How should I respond to these people? Come and try just a week with my group of painters. I am sure they would leave or burn out. They have no idea of what having a constant relationship with the guys entails ... all the human energy that requires... [1, female, age: 35-45, general culture teacher]

A second facet of macro-social-related challenges related to actual social dynamics that work against schools' educational role and against the educational task of teaching. For example, a few teachers complained about the emphasis in current society on a rapid approach to knowledge acquisition, which is perceived as an obstacle to authentic and deep learning. A third issue related to working policies that have an impact on salary and material working conditions for teachers. As also reported in other studies (e.g. Gu \& Day, 2013), if material conditions are not stable and secure, teachers' enthusiasm may be undermined, as they do not feel rewarded for doing their job.

Finally, seven individuals perceived curricular reforms as particularly stressful and challenging. In this regard, some teachers described the reforms as standardising factors, threatening their 'freedom of teaching' and consequently the perceived core or essence of their job. In the VET sector, this external requirement relates to reforms (based on the VET Law) that each professional curriculum has had to address in recent years in response to labour market needs. Teachers [2] reported feeling destabilised by the fact that they have had to change parts of their teaching programmes that they perhaps considered cornerstones of their subject.

With the new ordinances, there are a lot of changes that require you to question yourself. To revise your subject, to delete those parts of the programme that maybe you consider fundamental, essential cornerstones ... that you can't avoid ... but now the reforms ask you to delete these parts, and you cannot understand how to develop a competence without teaching those parts.... This is an objective difficulty, which destabilizes you. [2, male, age: 55-65, professional subject teacher]

The eso-system level includes difficult alliances with students' parents and company trainers. Many studies have identified difficult interactions with students' parents as an increasing problem for teachers (Beltman et al., 2011), although only a few teachers in the present study reported this problem as having a significant impact on their wellbeing. Similarly, interaction with students' company trainers was mentioned by a small group of participants as a source of conflict and dissatisfaction. In this regard, the main problems related to the students' assessment phase, as the evaluation frameworks of teachers and trainers on the job (who are usually expert employees with limited pedagogical experience) are sometimes conflicting or inconsistent. Discussion becomes particularly difficult where teachers perceive that workplace trainers consistently underestimate the value of school-based instruction.

At meso-system level, challenging situations were reported mainly in relation to work-life balance (see also Day, 2008) and teacher work-training balance, especially as teacher training is undertaken while already in-service. It is interesting that just one 
teacher mentioned the criticism concerning pressure from the labour market, which seemed likely to be of relevance in the Swiss VET system. The difficult relationship with extra-school services was mentioned especially in the context of very problematic students whose situation must be discussed within a network of experts.

A large number of the perceived difficulties reported by teachers referred to relationships within the micro-context of the school. This is unsurprising, as there is widespread evidence that stressful situations often arise in teachers' relationships with colleagues and with school principals (see Beltman et al., 2011). Teachers in our sample complained about conflicts and difficulties in collaborating with colleagues, and about the lack of a shared culture in the school. This issue of a lack of shared culture seemed to relate particularly to assessment procedures and to management and behavioural rules in the classroom. In addition, negative school leadership was mentioned by 17 teachers as a cause of profound professional crisis.

A majority of participants reported challenges in relation to classroom management, especially in the case of disruptive and challenging students. Almost all of the participants identified this factor as a source of major professional complexity that often proves difficult to handle. A variety of factors make students or classes hard to manage; these include students' behavioural and relational problems (including bullying of classmates and teachers), acts of violence or aggressive behaviours and students' emotional fragility and highly problematic life scenarios. Some participants reported that several of these conditions may overlap in a single class, and such problems can wear the teacher down if protracted over time.

Specific VET-related factors also play a central role in classroom management problems, including the poor professional motivation and engagement of some apprentices with their chosen profession. Students' lack of professional motivation and maturity can make it difficult for teachers to find the enthusiasm for interacting and teaching. This challenge affects certain VET sectors more than others; in our sample, low professional motivation was found especially in the commercial track [3].

The commercial sector is sometimes chosen when young people do not know what to do ... I mean, especially for girls, when they do not know what to do after compulsory school or they want to find employment as an aesthetician or a hairdresser or a florist ... and they can't find a contract ... commercial training is fairly suitable for everyone. On the contrary, it is difficult to become a bricklayer or a stonemason if you are not determined to do that ... in the commercial track, it's different; doors may open in different directions $\ldots$ and some end up in this track... [3, female, age: 35-45, professional subject teacher]

From a teacher's point of view, a lack of clear professional motivation in the student leads to feelings of anger and a sense of inadequacy and demotivation 'caused by the low motivation of apprentices', to the detriment of the whole class. Finally, disruptive events such as the death of a student, a suicide in the school or severe student addictions are also cited as threatening and stressful.

\section{Individual challenges}

At the individual level, five challenges related to attitudes to the profession - that is, how each individual interprets their educational role and professional identity. These challenges included difficulty in finding a balance between an excessively permissive 
and an authoritarian approach, being excessively emotionally involved with students, being a victim of one's sense of duty and perfectionism and lack of openness to change and the fear of being judged incompetent. These critical challenges echo what other authors have identified in different contexts (e.g. Richardson et al., 2013).

\section{Teaching-related challenges}

Three codes in the present study refer to the inner nature of the teaching profession and its characteristics - for instance, that it is an intense relational and emotional job. The fact that teaching can mean exposure to significant emotional and relational labour at risk to teachers' balance was cited by 23 teachers in 44 quotations. The most threatening factor related to perceived difficulties in the instruction process itself. This was cited in 73 quotations and by a majority of the sample (26 teachers), referring specifically to the need to adapt disciplinary knowledge to different practices and professional domains [4] and to adapt prior knowledge to the specific needs of the professional sector [5].

As a primary school teacher, I taught maths, in general. But mathematics in general is one thing; professional calculation is another. At the beginning, you do not feel good when you have electricians or bricklayers in front of you in professional calculation class. That's a kind of calculation you do not usually 'live'. Apprentices usually 'live' it at the workplace, but you do not live it! So, you have to make an effort, to search in their professional fields for the kind of calculation they need, and so on. And it is not an easy matter at the level of preparation. [4, male, age: 55-60, professional subject teacher]

However, I have to teach subjects that are not directly linked with 'my' subject. So, I have to design a lot of new lessons and courses. The existing material was poor and much too simple. So, I spent many nights and all my Saturday mornings and Sunday mornings studying professional calculation. It is clearly difficult to transfer subject-related knowledge to professional fields and in a differentiated way. [5, male, 35-45, general culture teacher]

Finally, the teachers mentioned a set of challenges dealing with their identity and role. For example, some referred to the demands of multiple overlapping roles as a teacher: educator, social worker, instructor and so on. For teachers, the boundaries of identity seem increasingly difficult to define and that can cause stress and fatigue.

\section{Perceived resources}

As shown in Table 3, we identified 23 categories of resources, which we grouped into 2 clusters: (a) context-related resources and (b) individual resources.

\section{Context-related resources}

Context-related resources were mentioned by many participants as a crucial support for their well-being, especially when facing critical situations. As in the case of challenges, contextual resources can be assigned to different system levels. At the eso-system level, a few people referred to how the alliance with students' company trainers helped to facilitate their work and interaction with students.

At the meso-system level, we found that many teachers' double involvement in teaching and in other professional activities outside school seems central. The ability to diversify their professional role, alternating school and extracurricular activities, was perceived as a positive support resource at both cognitive and emotional levels. By transferring 
Table 3. Perceived resources.

\begin{tabular}{|c|c|c|}
\hline Perceived resources & $N$ individuals & $N$ references \\
\hline \multicolumn{3}{|l|}{ Context-related factors } \\
\hline \multicolumn{3}{|l|}{ Eso-system level } \\
\hline - Alliance with students' company trainers & 5 & 6 \\
\hline \multicolumn{3}{|l|}{ Meso-system level } \\
\hline - 'Diversification' of professional roles & 14 & 38 \\
\hline - Opportunities for training & 22 & 45 \\
\hline \multicolumn{3}{|l|}{ Micro-system level } \\
\hline - Collegiality and positive relationship with colleagues & 31 & 85 \\
\hline - Positive school leadership and support & 19 & 47 \\
\hline - Intra-scholastic services and tools support (mentoring-mediation) & 18 & 31 \\
\hline - Students' motivation and gratitude & 16 & 20 \\
\hline \multicolumn{3}{|l|}{ Individual factors } \\
\hline \multicolumn{3}{|l|}{ Teaching competences } \\
\hline - Flexibility & 12 & 32 \\
\hline - Ability to motivate & 7 & 8 \\
\hline - Subject-specific teaching skills & 1 & 1 \\
\hline \multicolumn{3}{|l|}{ Relational competences } \\
\hline - Classroom management skills & 11 & 12 \\
\hline - Ability to create a positive dialogue with students & 18 & 31 \\
\hline - Identification and empathy with students & 9 & 11 \\
\hline - Ability to manage conflicts with colleagues and superiors & 5 & 6 \\
\hline \multicolumn{3}{|l|}{ Professional identity } \\
\hline - Intrinsic motivation and vocation & 11 & 29 \\
\hline - Perception of making a difference & 5 & 5 \\
\hline - Authenticity and coherence & 5 & 15 \\
\hline - Open minding and curiosity & 5 & 9 \\
\hline - Self-reflection and learning from experience & 8 & 14 \\
\hline \multicolumn{3}{|l|}{ General personal resources } \\
\hline - Self-care & 9 & 17 \\
\hline - Energy and persistence & 7 & 10 \\
\hline - Patience and self-control & 4 & 4 \\
\hline - Help seeking & 5 & 6 \\
\hline
\end{tabular}

professional experiences to school, this allows the development of flexible instructional competence [6]. Moreover, the possibility of teaching for a limited percentage of working time is often cited as important. By devoting the right energy to teaching (emotional level) while preserving the personal space in which to regenerate, teachers can avoid feeling burned out by everyday teaching problems or demotivated during a long career in teaching [7]. In this regard, the opportunity to invest one's energies in different professional activities - above all, after the first phase of one's teaching career - is also perceived as important, helping to keep school problems in perspective [8].

I feel lucky, as I do not teach full time, and so I have a lot of other activities that help me to see the positive side of teaching. By working outside school, you engage in various activities that you can bring to your classes, offering more inputs to students. And when you succeeded in linking practice with teaching, you find that they are more interested. [6, female, age: $35-45$, professional subject teacher]

So, in my opinion, it is important to have different activities and not to be obsessed only by teaching. This is an important resource that reinforces you. In the sense that you have different incentives, you can transfer these to class, too. In particular, this changes your attitude, as I think that full-time teachers are always a bit 'rigid' (laughing). So, maybe, working in a company, even for short periods ... diversifying a bit, so that you can see other activities that can be reported when teaching ... Because if you teach one subject for 30 years, you may lack incentives! [7, female, age: $35-45$, professional subject teacher] 
I'm convinced that you cannot do this job continuously for more than a certain number of years without changing anything!! Ten to fifteen years of teaching seems ideal, but then you need to break the mould in some way, maybe pairing further activities, inside or outside the school, 'breaking the pattern'-otherwise, it can become a cage. [8, male, age: 45-55, professional subject teacher]

Of the 37 participants, 22 cited training events as an additional resource, both for their specific contribution to professional development and as an opportunity to share reflections with colleagues.

Finally, the most mentioned contextual resources referred to the micro-system level, where collegiality and a positive atmosphere among colleagues were central, as mentioned by 31 teachers out of 37 . More specifically, participants emphasised the importance of establishing positive relationships with colleagues as a source of didactic and emotional support. In addition, management support was cited by 19 interviewees out of 37, who described encouragement and recognition by the school principal as crucial.

Other mentioned school supports included tutoring and mentoring (see also Meristo \& Eisenschmidt, 2014) - in the case of vocational schools in Switzerland, by so-called mediator teachers. Originally intended to support students psychologically and emotionally, they have become progressively more involved in supporting teachers as well.

Students' motivation and gratitude was said to contribute significantly to keeping teachers engaged and satisfied despite the difficulties they encounter. The students themselves are seen as a source of motivation for teachers, and the opportunity to make a difference in their complicated lives has an important impact on teacher engagement. This is well described in the following statement [9].

Despite everything, it is not the school that gives us the strength to carry on but the students. Because, you know, most of them make a lot of sacrifices to attend school. In my classroom, there are people who live on really low wages and in difficult life situations. And you see their sacrifices ... and we must help them. [9, female, age: 45-55, professional subject teacher]

The importance of making a difference in students' lives was also reported by Day, Sammons, Stobart, Kington and Gu (2007) as one of the key resources supporting teachers' resilience. This resource is especially relevant in VET schools, which are often attended by at-risk youth.

\section{Individual resources}

Turning to individual resources, we identified a number of elements, including teaching competences, relational competences, professional identity-related resources and general personal resources. First, the ability to be didactically flexible - to be able to easily adapt instructional plans and strategies to unexpected or changing situations - was identified as a crucial competence by many respondents when confronted by unmotivated classes or challenging students. At the same time and in line with this, teachers also mentioned the ability to motivate students beyond subject-specific skills. In terms of relational competences, participants referred to the ability to manage classroom dynamics, to create a positive dialogue with students, to value them as individuals and to empathise with them. 
The capacity to manage conflicts with both colleagues and superiors was also considered relevant because, as noted above, conflict situations are quite common in this domain. In particular, 5 of the 37 teachers emphasised the relevance of actively solving conflicts with colleagues and managers by being able to negotiate reciprocal needs, communicate effectively and be assertive.

With regard to professional motivation, the main driver in confronting difficulties seemed to be personal vocation - that is, a strong intrinsic motivation to teach, as reported in the review by Beltman et al. (2011) as one of the most important protective factors in maintaining well-being. Additionally, participants reported feelings of deep satisfaction when they were able to make a difference in the lives of young people and in society. Authenticity, open mindedness and reflectivity were also mentioned as helping teachers to successfully address professional challenges (see also Le Cornu, 2009). Finally, general personal resources with an emotional dimension were variously mentioned, including self-care strategies, the energy to persist and bounce back in the face of difficulties, self-control and the capacity to seek help.

\section{Discussion}

These perceived challenges and resources generally confirm the findings of previous research, supporting the hypothesis that most of VET teachers' difficulties and resources are shared with teachers in other sectors. Among perceived difficulties, multilevel factors were mentioned, from critical macro-level conditions (e.g. low social recognition) to challenging face-to-face relationships at school and in the classroom. Other problems related to difficulties with work-life balance and complicated relationships with other key actors (e.g. students' parents and company trainers). As reported by other scholars (Gu \& Day, 2013; Mansfield et al., 2014), negative adaptations were described mainly as a consequence of the interrelation, overlapping and persistence of a number of different factors rather than a single disruptive event or challenging condition. This insight is helpful in understanding the wide range of critical situations referred to during the interviews.

In terms of perceived resources, both contextual and individual protective factors were mentioned. In fact, although many individual factors were identified as contributing to teachers' resilience (e.g. teaching and relational competences, professional identity-related resources and general personal resources), the most cited factors referred to contextual conditions, including elements that related to school climate (e.g. collegiality, positive school leadership and students' gratitude) and services and supports for teachers (e.g. mediators, training initiatives). This finding confirms the need to consider how teachers' resilience results from the interdependence of the developing individual's beliefs and self-perceptions and the socio-cultural contextual variables and events that situate teachers' life and work ( $\mathrm{Gu} \& \mathrm{Li}, 2013)$.

Against this backdrop, a number challenges and resources have been identified as particular to VET teachers. First, the present study confirms that VET schools are perceived as a 'second choice', suitable for students who are less likely to succeed in academic paths. This condition is especially in evidence in the Italian-speaking part of Switzerland (Boldrini \& Bausch, 2009). As a first consequence, VET teachers feel that a lack of social support and recognition contributes to their increased frustration. In 
addition, teachers are often required to work with students who are challenging in terms of both motivation and achievement. To this respect, flexibility and ability to motivate students can be considered as resources that are particularly relevant for VET teachers.

A second finding is that pressure from the labour market was not directly perceived as a stressor. However, various related challenges were mentioned by the interviewees. For instance, VET teachers cannot simply be subject experts but must constantly develop links between the subject and its professional application, which is not straightforward for a subject expert but constitutes a pressing and urging task. In addition, these teachers must continuously engage to ensure adequate and up-to-date learning content with respect to developments in the related professional field. Additionally, the pressure teachers feel in responding to curricular reforms is seen in terms of a top-down process of standardisation of contents and the sacrifice of personal approaches to subject teaching in order to meet labour market needs.

Finally, in addition to teaching professional skills, VET teachers are asked to assist students in developing a proper professional identity. This is a demanding task that teachers are not always well prepared for. The fact that VET schools are frequently chosen as a 'last resort' may further undermine students' professional commitment. In particular, initial VET schools are attended by adolescents whose vocational identity maturity is quite weak and still developing.

Faced with such complexity, teachers consider it of a great value to be able to combine teaching with other activities and jobs, which is a structural condition peculiar to the Swiss VET system. Specifically, being involved in multiple jobs or activities provides teachers with emotional, cognitive and pedagogical support by helping to increase their engagement and satisfaction when dealing with everyday professional problems.

\section{Implications and limits}

In line with the recommendations of other scholars, our findings suggest a need to approach teacher resilience in an ecological, relational and systemic way (Griffiths \& Edwards, 2014; Gu, 2014; Mansfield, Beltman, Price, \& McConney, 2012). From this perspective, multilevel and holistic interventions must be encouraged to improve multiple resources rather than working exclusively on individual resilience skills. Despite the exploratory nature of this study, some specific recommendations can be made in respect of VET teachers.

First, VET teachers need particular support to successfully negotiate between their disciplinary knowledge and the practical competences required by the related professional field. Those skills should be considered when designing education programmes for VET teachers. Second, greater social recognition of VET schools and teachers would be beneficial in encouraging teachers when they encounter professional difficulties. However, this will require a cultural change that is complex to activate. Our findings also suggest the importance of creating structural conditions that facilitate teachers' involvement in activities other than teaching. From this perspective, multiple roles and activities can be promoted within schools - for example, by involving expert teachers in school management or in tutoring initiatives for new teachers. Additionally, 
opportunities for external experiences - of even short duration - should be promoted to teachers (Sappa, Boldrini, \& Aprea, 2015).

Finally, the study has a number of limitations. The small and non-representative sample did not allow us to generalise our findings. In addition, the analysis was strictly explorative, resulting in a descriptive overview of perceived challenges and resources. Further analysis will be needed to understand the reciprocal relationship between difficulties, resources and positive adaptation. The second phase of the project, involving a large survey based on these findings, will investigate this complexity.

\section{Disclosure statement}

No potential conflict of interest was reported by the authors.

\section{Notes on contributors}

Elena Boldrini is teachers'educator and senior researcher at the Swiss Federal Institute for Vocational Education and Training (SFIVET) in Lugano, Switzerland. She got a master degree in Communication sciences applied in training contexts (Università della Svizzera Italiana, Lugano - Switzerland) and a PhD in social sciences (Università dell'Insubria, Varese - Italy). Her research and teaching interests include mainly: teachers' resilience, situation-based learning, teaching analysis of practices through video-annotation.

Viviana Sappa is teachers' educator and senior researcher at the Swiss Federal Institute for Vocational Education and Training (SFIVET) in Lugano, Switzerland. She got her PhD in Social and Developmental Psychology at the University of Turin, Italy. Her research interests include in teachers' resilience, art-based learning, motivation to learn and integrated learning.

Carmela Aprea is full professor of Business and Economic Education at the University of Mannheim, Germany. She holds a Master's degree from the Goethe University Frankfurt (Germany) and a $\mathrm{PhD}$ from the University of Mannheim. Her research interests include: resilience in work and learning settings, financial and economic literacy education as well as technology-enhanced learning and teaching in business and economics education.

\section{References}

Beltman, S., Mansfield, C., \& Price, A. (2011). Thriving not just surviving: A review of research on teacher resilience. Educational Research Review, 6, 185-207.

Boldrini, E., \& Bausch, L. (2009). Transizioni dopo la scuola dell'obbligo in Ticino: Le scelte dei giovani. Rivista svizzera di scienze dell'educazione (RSSE), 3(21), 287-316.

Bonica, L., \& Sappa, V. (2010). Early school-leavers microtransitions: Toward a competent self. Education + Training, 52(5), 368-380.

Bronfenbrenner, U. (1979). The ecology of human development: Experiments by design and nature. Cambridge: Cambridge University Press.

Brunetti, G. J. (2006). Resilience under fire: Perspectives on the work of experienced, inner city high school teachers in the United States. Teaching and Teacher Education, 22, 812-825.

Day, C. (2008). Committed for life? Variations in teachers' work, lives and effectiveness. Journal of Educational Change, 9(3), 243-260.

Day, C. (2014). Resilient principals in challenging schools: The courage and costs of conviction. Teachers and Teaching, 20, 638-654. 
Day, C., \& Gu, Q. (2009). Teacher emotions: Wellbeing and effectiveness. In M. Zembylas \& P. Schutz (Eds.), Advances in teacher emotion research: The impact on teachers' lives (pp. 15-31). Dordrecht: Springer.

Day, C., Sammons, P., Stobart, G., Kington, A., \& Gu, Q. (2007). Teachers matter: Connecting lives, work and effectiveness. New York: McGraw Hill.

Dworkin, A. G. (2009). Teacher burnout and teacher resilience: Assessing the impacts of the school accountability movement. In L. J. Saha \& A. G. Dworkin (Eds.), International handbook of research on teachers and teaching (pp. 491-510). Boston, MA: Springer.

Ebersöhn, L. (2014). Teacher resilience: Theorizing resilience and poverty. Teachers and Teaching, 20, 568-594.

Gibbs, A. S., \& Miller, A. (2014). Teachers' resilience and well-being: A role for educational psychology. Teachers and Teaching, 20(5), 1-13.

Gonon, P. (2011). Apprenticeship as a model for the international architecture of TVET. In Z. Zhao, F. Rauner, \& U. Hauschildt (Eds.), Assuring the acquisition of expertise: Apprenticeship in the modern economy (pp. 33-42). Beijing: Foreign Language Teaching and Research Press.

Griffiths, A. (2014). Promoting resilience in schools: A view from occupational health psychology. Teachers and Teaching, 20(5), 655-666.

Griffiths, A., \& Edwards, A. (2014). Special issue: Teachers and resilience: Interdisciplinary accounts. Teachers and Teaching, 20(5), 499-501.

$\mathrm{Gu}, \mathrm{Q}$. (2014). The role of relational resilience in teachers' career-long commitment and effectiveness. Teachers and Teaching, 20(5), 502-529.

Gu, Q., \& Day, C. (2007). Teachers resilience: A necessary condition for effectiveness. Teaching and Teacher Education, 23, 1302-1316.

Gu, Q., \& Day, C. (2013). Challenges to teacher resilience: Conditions count. British Educational Research Journal, 39(1), 22-44.

$\mathrm{Gu}$, Q., \& Li, Q. (2013). Sustaining resilience in times of change: Stories from Chinese teachers. Asia-Pacific Journal of Teacher Education, 41, 288-303.

Guest, D. E., Oakley, P., Clinton, M., \& Budjanovcanin, A. (2006). Free or precarious? A comparison of the attitudes of workers in flexible and traditional employment contracts. Human Resource Management Review, 16(2), 107-124.

Krippendorff, K. (2013). Content analysis. An introduction to its methodology (3rd ed.). London: Sage.

Le Cornu, R. (2009). Building resilience in pre-service teachers. Teaching and Teacher Education, 25, 717-723.

Luthar, S., Cicchetti, D., \& Becker, B. (2000). The construct of resilience: A critical evaluation and guidelines for future work. Child Development, 71, 543-562.

Mansfield, C., Beltman, S., Weatherby-Fell, N., \& Broadley, T. (2016). Classroom ready? Building resilience in teacher education. In R. Brandenburg, S. McDonough, J. Burke, \& S. White (Eds.), Teacher education (pp. 211-229). Singapore: Springer.

Mansfield, C. F., Beltman, S., \& Price, A. (2014). 'I'm coming back again!' The resilience process of early career teachers. Teachers and Teaching, 20(5), 547-567.

Mansfield, C. F., Beltman, S., Price, A., \& McConney, A. (2012). "Don't sweat the small stuff:" Understanding teacher resilience at the chalkface. Teaching and Teacher Education, 28, 357-367.

Marshall, M. N. (1996). Sampling for qualitative research. Family Practice, 13(6), 522-525.

Masten, A., Best, K., \& Garmezy, N. (1990). Resilience and development: Contributions from the study of children who overcome adversity. Development and Psychopathology, 2, 425-444.

Meristo, M., \& Eisenschmidt, E. (2014). Novice teachers' perceptions of school climate and selfefficacy. International Journal of Educational Research, 67, 1-10.

Richardson, P. W., Watt, H. M. G., \& Devos, C. (2013). Types of professional and emotional coping among beginning teachers. In M. Newberry, A. Gallant, \& P. Riley (Eds.), Emotion and school: Understanding how the hidden curriculum influences relationships, leadership, teaching, and learning (Advances in research on teaching, volume 18) (pp. 229-253). Bingley: Emerald Group Publishing. 
Rutter, M. (2006). Implications of resilience concepts for scientific understanding. Annuals of the New York Academy of Science, 1094, 1-12.

Sappa, V., Boldrini, E., \& Aprea, C. (2015). Combining teaching with another job: A possible resource to face professional challenges. Preliminary findings from a Swiss study in vocational education and training. Empirical Research in Vocational Education and Training, 7, 13.

Schelvis, R. M. C., Zwetsloot, G. I. J. M., Bos, E. H., \& Wiezer, N. M. (2014). Exploring teacher and school resilience as a new perspective to solve persistent problems in the educational sector. Teachers and Teaching, 20(5), 622-637.

Swiss Confederation (2002). Vocational and Professional Education and Training Act (VPETA). Retrieved July 07th, 2017, from http://www.admin.ch/ch/e/rs/412_10/index.html.

Ungar, M. (Ed.). (2012). The social ecology of resilience: A handbook. New York, NY: Springer.

Vähäsantanen, K., \& Eteläpelto, A. (2009). Vocational teachers in the face of a major educational reform: Individual ways of negotiating professional identities. Journal of Education and Work, 22(1), 15-33. 
Teachers and

TEACHING

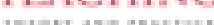

Teachers and Teaching

theory and practice

\section{Which difficulties and resources do vocational teachers perceive? An exploratory study setting the stage for investigating teachers' resilience in Switzerland}

\section{Elena Boldrini, Viviana Sappa \& Carmela Aprea}

To cite this article: Elena Boldrini, Viviana Sappa \& Carmela Aprea (2018): Which difficulties and resources do vocational teachers perceive? An exploratory study setting the stage for investigating teachers' resilience in Switzerland, Teachers and Teaching, DOI: 10.1080/13540602.2018.1520086

To link to this article: https://doi.org/10.1080/13540602.2018.1520086

View supplementary material $₫$

Published online: 17 Sep 2018.

Submit your article to this journal $\sqsubset$

View Crossmark data $\nearrow$ 